\title{
Occupational Health and Safety Status in the Windhoek Construction Industry: A Namibian Perspective
}

\author{
Emma Maano Nghitanwa ${ }^{*}$, Lindiwe Zungu² \\ ${ }^{1}$ School of Nursing, University of Namibia, Windhoek, Namibia \\ ${ }^{2}$ Department of Health Studies, University of South Africa, Pretoria, South Africa \\ Email: *enghitanwa@unam.na
}

How to cite this paper: Nghitanwa, E.M. and Zungu, L. (2017) Occupational Health and Safety Status in the Windhoek Construction Industry: A Namibian Perspective. Open Journal of Safety Science and Technology, 7, 113-127.

https://doi.org/10.4236/ojsst.2017.73011

Received: June 17, 2017

Accepted: September 9, 2017

Published: September 12, 2017

Copyright ( 2017 by authors and Scientific Research Publishing Inc. This work is licensed under the Creative Commons Attribution International License (CC BY 4.0).

http://creativecommons.org/licenses/by/4.0/

\begin{abstract}
Construction industry remains the dangerous industry in the world, due to the nature of work and the working environment which exposes workers to different types of hazards and occupational accidents. Construction workers are also at risk of developing occupational related health conditions due to the exposure to occupational hazards. A cross-sectional, quantitative, descriptive study was conducted to collect the data regarding occupational health and safety status in the construction industry. Data was collected with questionnaires developed based on the literatures and the World Health Organization Healthy workplace model. The study found out that the provision of occupational health and safety in the Windhoek construction industry is in poor status. Furthermore, construction work is mainly for male, young workers aged between 18 to 29 years. The mean age is 31.48 years. The study results also indicated that occupational hazards are prevalent in the construction industry. Nevertheless, most participants indicated that occupational accidents are not common in the construction sites. The study recommended the development of practical guidelines to improve the occupational health and safety status in the construction industry. The recommended guidelines should be implemented in all construction sites.
\end{abstract}

\section{Keywords}

Construction, Hazard, Industry, Occupational Health, Occupational Safety

\section{Introduction}

Construction industry is regarded as dangerous industry in the world due to the 
higher number of occupational accidents, injuries and diseases in the sector than any other sectors [1]. In addition, the construction industry offers hazardous and dangerous occupations, which expose construction workers to several hazards and risks [2] such as asbestos, lead, vibration, silica dust, dust and noise [3]. Meanwhile, [4] note that the construction industry's hazards cause financial losses and personal injuries which may affect the health status of construction workers and the duration of the construction project. As a result, the unfortunate situations of occupational injuries, accidents and diseases affect the productivity and the economic status of the countries in a negative way [4].

According to the United States Department of Labour's 2010 Bureau of Labour Statistics, occupational hazards, such as falls from height, were higher and accounted for $14 \%$ of the fatal construction industries injuries in the USA [5]. Furthermore, construction work takes place mostly on open environments which exposes the construction workers to bad weather conditions such as a cold, windy or hot environment [2] and may lead to occupational accidents and work related diseases [6]. Construction workers are also at risk of developing common occupational diseases such as back pain, asthma, Noise Induced Hearing Loss (NIHL) and cancers which could be avoided if employees and workers set up and implement occupational health and safety preventive measures [7]. Construction-related accidents and diseases are mostly associated with unsafe activities or behaviour among workers and employers [8]. Furthermore, occupational accidents may result in numerous damages and losses such as in worker's compensation and medical services payments [4].

The construction industry exposes workers to health risks which may cause construction workers to develop work-related health problems [9]. A study by Järvholm and Aström [10] indicates that vibration white finger, carpal tunnel syndrome, occupational deafness and dermatitis are the most common cases of non-lung diseases in the construction industry. Furthermore, other substances that cause occupational diseases in the construction industries include carcinogenic and teratogenic such as lead chromate, dichloromethane, asbestos and carbon monoxide from welding work [11]. As a result, compared to other industrial sectors, the construction industry has the largest number of occupational cancer due to exposures to asbestos and silica [12].

The most common health problems in developing countries, are deafness and musculoskeletal disorders, which are a result of exposure to hazards. Therefore, governments should put up measures to ensure OHS compliances in order to prevent occupational related health problems [13]. Meanwhile, construction workers, especially workers aged 40 to 50 years old, often suffer from back pain and other musculoskeletal problems than other workers in other industries [14]. This claim is substantiated by the findings from a survey carried out in Cape Town, South Africa which reveals that back pain among workers in construction companies occurred at a rate $25 \%$ more than in the developed countries which leads to absenteeism and low productivity [15]. 
A study by Smallwood [16] that determines South African architects' designer's perceptions and practices regarding construction ergonomics shows that building designers lack of knowledge and awareness of OHS in the construction industry contributes to occupational diseases such as back pain as most of designers were not trained on OHS during their tertiary education. In addition, the study realised the importance of architectural design pertaining to ergonomics in the construction industry. The study also recommends the inclusion of construction ergonomics in architectural designer tertiary education and advocates for the strengthening of continuing professional development [16].

In Namibia studies that investigated occupational accidents, injuries, fatalities and diseases in the construction industry are very limited and statistics regarding occupational diseases for construction workers from the Ministry of Health and Social Services of Namibia were not identified. However, the rate of occupational injuries and fatalities in the Namibia construction industry is higher when compared to other industries [17]. Furthermore, the Ministry of Labour and Social Welfare of Namibia has raised a concern after workplaces inspections during the period of 2013/2014. It was identified that employers were not reporting occupational accidents and injuries which were possibly due to employers' ignorance to report accident or fear of repersecution [17]. On the other hand, in Namibia, statistical data on occupational related diseases from the construction industry is non-existent [18].

According to the Regulations relating to health and safety of employees at work (No 156 of 1997) the employer is required to provide adequate toilet and washing facilities, resting rooms and a clothes storing area in order to benefit the OHS of workers, in Namibia [19]. Furthermore, clean drinking water should be provided. However, a study conducted in India to investigate the constraints and opportunities faced by women in the construction industry reveals that $55 \%$ of the participants stated that basic facilities such as toilet and drinking water were not provided in $64 \%$ of the construction sites [20]. In contrast, the results from a study by Irumba, in Unganda construction industry [21] reveal that $90 \%$ of the inspected construction sites were found to be providing drinking water.

Provision of Personal Protective Equipment (PPE) is important in ensuring OHS at workplaces, especially, when properly selected and used by workers, as they provide protection against risks [22]. The proponents of OHS advocate for the use of protective equipment by workers, including the use of face masks to protect against dust inhalation [23]. PPE should be used as a control measure but not to eliminate the hazard during construction work [24]. Lack and inappropriate use of PPE due to unavailability or ignorance also contributes to the increase in occupational diseases, injuries and fatalities in the construction industry [25]. In addition, it was revealed by the study conducted in Taiwan, that $38 \%$ of workers in the construction industry do not use PPE correctly [25] which is a sign of ignorance or unsafe acts or lack of knowledge. Lack of PPE use was also reported as contributing to $54.5 \%$ accidents in the construction industry [26] as some employers do not provide PPE to their workers, while some work- 
ers prefer not to use them even if they have been supplied by their employers [27]. Therefore, it is the employer's responsibilities to ensure that workers are supervised on wearing safety tools when performing jobs at construction sites, even though workers should be informed to take responsibility for their own health and safety especially by imposing punishment if they are not adhering to safety rules [28].

This ground-breaking study provides a description of the current OHS status of the construction companies in Windhoek, Namibia. It is envisaged that the study will facilitate the improvement of OHS in the country's construction sector. Very little is known about the OHS status of Namibia's construction industry, hence, this study will offer a chance for policy makers to appreciate better the OHS situation in the construction industry and the ways in which the sector can be improved as suggested in the study findings.

The purpose of the study was to investigate the occupational health and safety status in the construction industry of Windhoek, Namibia. The study objectives were to assess the socio-demographic characteristic of the construction workers in Windhoek, Namibia and to assess the occupational health status in the construction industry of Windhoek, Namibia.

\section{Material and Methods}

A quantitative, cross-sectional, exploratory and contextual study design was used in this study to describe the OHS status in the construction industry of Windhoek, Namibia. The study's setting included all construction workers in the construction sites in Windhoek, Namibia which were in operation during the time of data collection. The target population consisted of all construction workers in the construction sites operating during the time of data collection in Windhoek, Namibia. The researchers obtained the lists of names of all construction workers from the site managers for thirteen construction sites operating during the study and were used as samplings frames. Census sampling was employed by recruiting all 1097 construction workers who were available during data collection time to participate in the study. However, only 549 construction workers agreed to participate in the study.

Data was collected by the researchers for a period of six months from October 2014 to March 2015. The data was collected using face to face interviews, using a self-designed structured questionnaire. The questionnaire was developed based on the reviewed literature and the World Health Organization Healthy workplace model, the framework underpinned this study [29]. A questionnaire with 49 items was collect data among workers in construction industries targeted for this study, considering the study objectives. The main content included close ended questions which deals with socio-demographic characteristics, occupational health and safety hazards, occupational accidents, OHS provision on the construction industry as well as work-related health problems faced by participants in the construction industry. 
A professional statistician assisted the researcher with data analysis using the Statistical Package for the Social Sciences (SPSS) version 23. Descriptive statistics were used to describe the OHS situation in the Windhoek construction industry.

\section{Results}

\subsection{Socio-Demographic Characteristics of Construction Workers}

The analysis, as indicated in Table 1 , shows that $88.3 \%$ of the participants in this

Table 1. Participant's socio-demographic characteristics $(\mathrm{N}=549)$.

\begin{tabular}{|c|c|c|}
\hline Characteristic of participants & Frequencies (n) & Percentage (\%) \\
\hline $\begin{array}{c}\text { Gender } \\
\text { Male }\end{array}$ & 485 & $88.3 \%$ \\
\hline Female & 64 & $11.7 \%$ \\
\hline \multicolumn{3}{|l|}{ Age groups of workers in years } \\
\hline $18-29$ & 235 & $42.8 \%$ \\
\hline $30-39$ years & 229 & $41.9 \%$ \\
\hline 40 - 49 years & 83 & $15.1 \%$ \\
\hline 50 - 59 years & 2 & $0.4 \%$ \\
\hline \multicolumn{3}{|l|}{ Marital status } \\
\hline Single & 364 & $66.2 \%$ \\
\hline Married & 137 & $25 \%$ \\
\hline Divorced & 14 & $2.6 \%$ \\
\hline Widowed & 4 & $0.7 \%$ \\
\hline Separated & 8 & $1.5 \%$ \\
\hline Cohabiting & 22 & $4 \%$ \\
\hline \multicolumn{3}{|l|}{ Education level } \\
\hline None & 32 & $5.8 \%$ \\
\hline Primary & 210 & $38.3 \%$ \\
\hline Secondary & 275 & $50.1 \%$ \\
\hline Tertiary & 35 & $5.8 \%$ \\
\hline \multicolumn{3}{|l|}{ Occupation status } \\
\hline Bricklayer & 124 & $22.6 \%$ \\
\hline Painter & 66 & $12 \%$ \\
\hline Electrician & 29 & $5.3 \%$ \\
\hline Plumber & 62 & $11.3 \%$ \\
\hline Engineer & 7 & $1.2 \%$ \\
\hline Carpenter & 70 & $12.8 \%$ \\
\hline Labourer & 123 & $22.4 \%$ \\
\hline Driver & 15 & $2.7 \%$ \\
\hline Other & 53 & $9.7 \%$ \\
\hline \multicolumn{3}{|l|}{ Employment Type } \\
\hline Permanent & 400 & $72.9 \%$ \\
\hline Fixed & 83 & $15.1 \%$ \\
\hline Casual & 66 & $12 \%$ \\
\hline
\end{tabular}


study were males and $11.7 \%$ were females. The participants' age group distribution consists of $42.8 \%$ participants aged between 18 and 29 years followed by $41.7 \%$ occupying the $30-39$ age range. The mean overall age is 31.48 years. Furthermore, of these workers, $66.2 \%$ were single, while $25 \%$ were married.

The participants' educational background and their respective occupations, were also analysed. The findings show that $50.1 \%$ participants had secondary education, while $38.3 \%$ participants had attained a primary level education qualifications. The analysis shows further the participants "occupations as follows: $22.6 \%$ bricklayers, $22.4 \%$ labourers, $12.8 \%$ carpenters, $12 \%$ painters, $11.3 \%$ plumbers, $9.7 \%$ other category of construction workers, 5.3\% electricians, $2.7 \%$ drivers, and $1.2 \%$ were engineers. Finally, the analysis also shows that $72.9 \%$ of the participants were permanent workers, $15.1 \%$ were employed on fixed contract, while $12 \%$ were casual workers.

\subsection{Occupational Health and Safety Hazards in the Construction Industry}

Participants were asked if physical hazards were present on the construction sites and the findings are illustrated in Figure 1. The analysis shows that $94.9 \%$ of the participants indicated the presence of noise on their construction sites. In addition, the analysis reveals that dust posed as a physical hazard at the construction sites as stated by $94.2 \%$ of the participants. Furthermore, the analysis shows that, (92.5\%) of the participants indicated vibration as one of the types of physical hazards present at their construction sites. Lastly, the analysis shows that $94.2 \%$ of the participants indicated that chemical hazards, such as paints, were present at the construction sites.

Participants were asked to indicate whether psychosocial hazards, such as discrimination and victimisation had ever happened on the construction sites. The analysis reveals that, $10.2 \%$ of the participants indicated that discrimination had

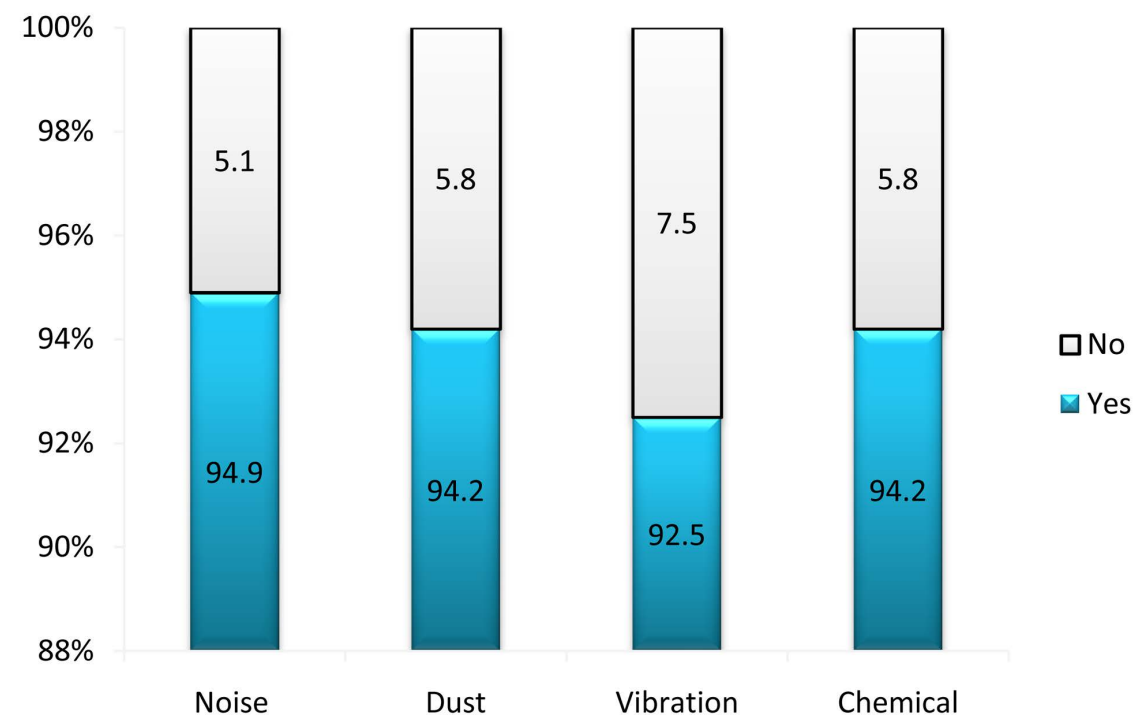

Figure 1. Nature of physical and chemical hazards at the construction sites $(\mathrm{N}=549)$. 
happened at their worksites. Furthermore, the analysis shows that only $8.6 \%$ of the participants indicated that victimisation had ever happened on the construction sites.

\subsection{Nature of Occupational Accidents at Construction Sites}

The analysis shows that falls from above were reported by $21.3 \%$ of the participants and $15 \%$ participants confirmed the occurrence of cut by machinery. The analysis also shows that $12.9 \%$ of the participants confirmed witnessing incidents of sticking by falling objects at their construction sites. The analysis of data on the question whether struck-by-moving-objects accidents had transpired at the construction sites indicated that $10.9 \%$ of the participants agreed and electrocution was reported by $11.1 \%$ of the participants.

Participants were also asked about motor vehicle accidents at the construction sites. In this regard, the analysis shows that $8.9 \%$ of the participants had experienced motor vehicle accidents in their respective sites. Lastly, participants were asked about the experience of trench burying on the construction sites, and the analysis of the responses demonstrated that $8.7 \%$ of the participants reported that trench burying accidents had ever happened at their construction sites. The results regarding occupational accidents are illustrated in Figure 2.

\subsection{Occupational Health and Safety Provision on the Construction Industry}

Participants were asked to indicate if they whether provided with certain amenities regarding OHS such as welfare facilities and PPE. The question regarding if toilet facilities were provided in the construction sites an analysis of the responses shows that $96.9 \%$ of the participants confirmed that toilet facilities were provided at the construction sites. Further analysis of the response data shows

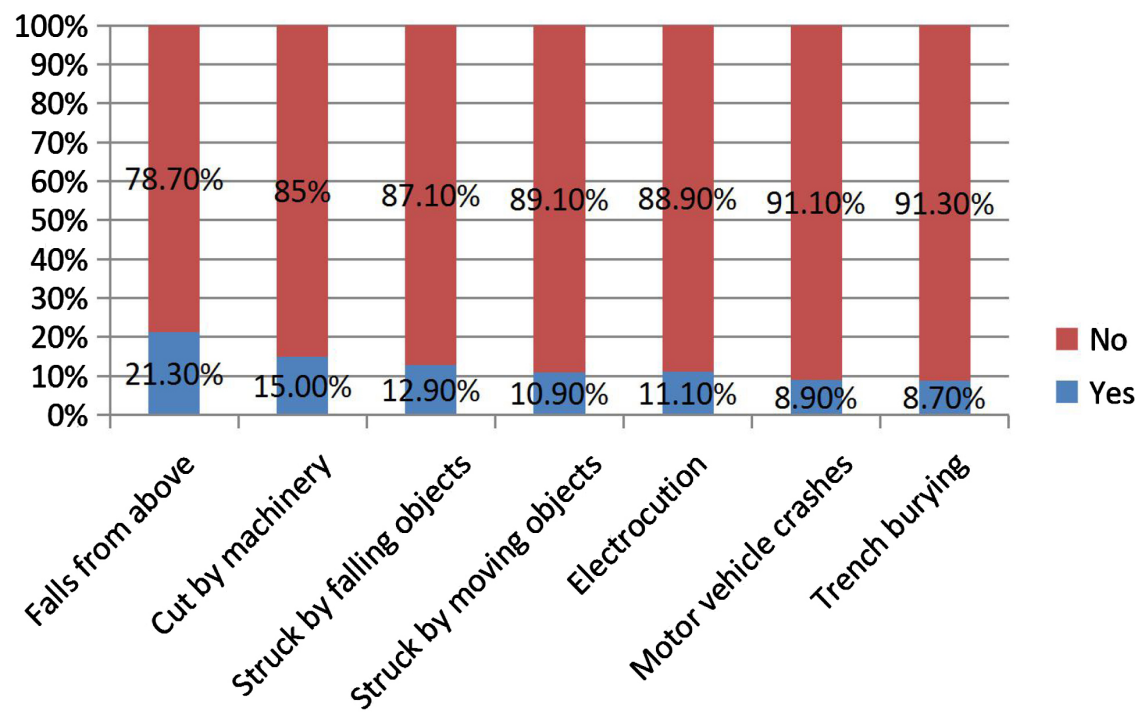

Figure 2. Occupational accidents in the construction industry as reported by participants $(\mathrm{N}=549)$. 
that $48.8 \%$ of the participants indicated that toilets were demarcated for males and females as per Regulations relating to the health and safety of employees at work (Regulation 156 of 1997). However, the analysis shows that $28.1 \%$ of the participants stated that hand washing soaps were available in the toilets. Meanwhile, $96.0 \%$ of the participants confirmed that they were getting rest breaks, however, only $19.5 \%$ participants indicated that rest rooms were available on their respective construction sites. Lastly, the analysis further indicates that 89.3\% of the participants confirmed the non-existence of designated smoking areas at their respective construction sites.

On the question whether participants were provided with PPE at work $82.9 \%$ of the participants agreed that PPE were provided at work. Furthermore, $12 \%$ of the participants usually made personal payments to get PPE. Further, $83.4 \%$ of the participants indicated that PPE were fitting properly and $82.3 \%$ of the participants felt comfortable while wearing PPE. The data gathered from the question about whether participants were given replacements when PPE is worn out was analysed and the results show that $77.2 \%$ of the participants confirmed having been given replacements after their PPE had worn out. Finally, the analysis regarding participants' use of PPE while performing their work indicates that $75.6 \%$ participants stated that they were using PPE during their work.

\subsection{Nature of Work-Related Health Problems Faced by Participants}

Participants were asked to indicate whether they had experienced any work-related health problems, such as back pain, skin problems, and difficulties in breathing or hearing complications during the six months prior to the study. The analysis shows that $58.1 \%$ participants had suffered from back pain, $23.1 \%$ participants reported that they had had breathing difficulties. The analysis shows further that $18.8 \%$ of the participants had experienced skin problem and $7.7 \%$ of the participants had difficulties in hearing.

\section{Discussion}

\subsection{Participant's Socio-Demographic Characteristics}

The findings from this current study showed that male participants were significantly more that female participants. This finding is consistent with several demographic data about the construction industries such as that found in Hong Kong [8], as well as the demographic data evident in Watts [30] study on women managers in the UK construction industry and that by [31] examining workers' alcohol use in male-dominated industries in Australia, which all underscore that the construction industry is male dominated. However, [21] study reflects contrasting demographics findings as it states that the construction industry in India is female dominated with women constituting $51 \%$ of the construction workers.

The findings revealed that more than two-fifths of the participants were aged between 18 and 39 years. This study finding is almost similar to that from a 
study conducted on Tanzania's construction industry where $56.3 \%$ of the participants were in the 25 - 35 age range [32]. Similarly, Miller's [5] studies which assess the educational safety training solutions for Latino construction workers found out that an overwhelming majority $78 \%$ of the participants were younger than 40 years. However, the current study finding contrasts with that from the studies conducted on South Africa's construction industries [33] and South Korea [34] in which the majority of participants were found aged above 40 years.

The current study findings indicated that just below two-thirds of the participants were single. The findings concur with that from the study conducted on the Portuguese construction industry which stated that the industry mostly employs single young men [35]. This current study finding is however, unlike that from [24] in their study on accidents among electricity distribution company workers in Iran, and [4] on ways to reduce occupational injuries in the Taiwanese construction industry, which both show that $63 \%$ and $63.7 \%$ construction workers, respectively, were married.

The findings regarding the education level show that just above half of workers in the construction industry obtained secondary education. The findings are in agreement with those from the study conducted on the Saudi Arabian construction industry that revealed that $45.5 \%$ of the participants completed secondary education while $33.3 \%$ completed primary education [36]. Unlike with the current study [32] on the Tanzanian construction industry found out that less than half of the workers had completed primary education. Furthermore, the study conducted by Rahmani et al. [26] on Iran's construction industry also noted that most of the participants $46.2 \%$ had diploma qualifications.

This current study finding indicated that bricklayers represent the highest number of workers followed by labourers. Similar findings have been reported in a study conducted by Himalowa and Frantz [15] in their assessment of the functional activities effect on occupationally-related low back pain among male manual workers in South Africa's construction industry, which shows that $46 \%$ of the participants were masons. However, the findings of this current study are different from the findings of a survey conducted among Saudi Arabian construction workers, which indicated that the majority of participants were manual labourers (25.5\%) and that these were followed by plumbers (17\%) [36]. Another finding from the study conducted by Herbert and Iipumbu [37] in Namibia shows that the majority of participants were labourers.

The findings of the current study indicated that the majority of participants were employed on a permanent basis. This contradicts several authors' that stated that the majority of construction workers work on a temporary or casual basis [13], a situation also noted by Phoya [30] with regard to Tanzania. Nevertheless, the study conducted among the Chinese construction industry in Namibia shows that the majority of workers did not know whether they were recruited on casual or permanent basis as they were not informed about their employment status by the employers with some not having contracts at all [37]. 


\subsection{Occupational Health and Safety Hazards in the Construction Industry as Reported by Participants}

The current study showed that the significant majority of participants indicated that noise was a common physical hazard at the study sites. This study finding is also evident in [38] observations in the Netherland, where noise is also noted as a common health hazard in the construction industry. Opposing this current study finding, however, is the research conducted [39] on Spanish construction industry where only $36.53 \%$ of the participants indicated the presence of noise at the construction sites. Dust was indicated by participants as a common physical hazard at the study sites. Similarly, a study on the construction industry of low and middle income countries [7] reported findings that dust is a common physical hazard in the construction industry.

The findings from the current study revealed that the majority of participants indicated that vibration was not a common hazard at the study sites. The findings are similar with that from a previous study in Spain which found out that only one-fifth of the participants reported the presence of vibration at the construction sites [39]. In contrast, participants in the study determining the knowledge of Whole-body vibration among OHS professionals in the USA indicated that vibration is a common physical hazard in the construction industry [40]. In addition, the study on the assessment of the effectiveness of drill machine handle coating on vibration transmissibility in India indicated vibration as a common hazard in the construction industry [41].

It emerged, from the findings of this current study that, an overwhelming majority of the participants indicated that chemical hazards were present at the study sites. The findings are similar to those from studies conducted on the construction industry, such as the study on knowledge and research information sharing on construction health and safety practices in Malaysia [42], and study on Tanzania's construction industry [32], which both reported the prevalence of chemical hazards in the industry. The results of this study showed very few cases of discrimination and victimisation at the study sites. On the contrary, several studies have shown that discrimination and victimisation is a common psycho-social hazard in the construction industry as noted in [37] on Namibia, and [32] on Tanzania.

\subsection{Nature or Type of Health Problems}

The current study findings indicated that back pain was experienced by three-fifths of the participants. This finding is in agreement with that from a study by Alghadir and Anwer [36] which assesses the prevalence of musculoskeletal pain among Saudi Arabian construction workers that revealed that 50\% participants had back pain. In addition, [41] investigated MSDs among Netherlands' construction workers and found out that back pain is a common health problem as it was reported by $53 \%$ of the bricklayers and $33 \%$ of the supervisors. Nevertheless, leg pain was reported as a common health problem by $35 \%$ of the partici- 
pants in the study by [43] on the Saudi Arabian construction industry, compared to $31.2 \%$ who had reported on suffering from back pain.

The current study's results indicated that a few participants reported that had difficulties in breathing. The current study finding concurs with that from [44] study on occupational diseases and public health concerns of migrant construction workers in India, where by $7.7 \%$ of the participants reported respiratory problem as a common health problem. Furthermore, a study on the USA's construction industry reported difficulties in breathing as a common health problem [3]. It emerged that, from the findings of this current study, only a few participants amounting to one-fifth of the total participants indicated that they had experienced skin problems. The prevalence of skin problem as ales common ill health in the construction industries is also noted in the study conducted [45] on the Indian construction industry, where it is reported on by $5 \%$ of the construction worker participants.

The current study's findings show that a few participants had experienced difficulties in hearing. The findings are supporting the study conducted [22] to assess the construction workers awareness of occupational hazards, illness and injuries associated with the construction industry in Mombasa, Kenya, which found out that very few (3.3\%) construction workers had hearing impairments.

\subsection{Occupational Health and Safety Provision at the Construction Sites}

It emerged from the findings of the current study that an overwhelming majority of participants indicated that toilet facilities were provided at the study sites. In contrast to this study's finding, inadequate welfare facilities in the construction industry were reported by $55 \%$ of the participants in [20] study among women in India's construction industry. Moreover, Abrey and Smallwood's [46] study on the assessment of the effects of unsatisfactory working condition on the construction industry's productivity in South Africa, reported that there is lack of adequate welfare facilities in the construction industry.

This current study showed that the majority of the participants indicated that they were provided with PPE, free of charge. The findings are also confirmed in related literatures such as [32] which indicate that workers were provided with PPE in one construction site studied as case study. This observation contradicts the findings from the study on the Chinese investments in Namibia, where they state that the majority of construction workers were not provided with PPE [37]. The current study showed further that the majority of participants stated that they were regularly using PPE during their work activities. This current study finding concurs with the findings by [47] regarding the Indian construction industry where $68.1 \%$ of the participants indicated that used PPE regularly. However, the current study results differ with [32] study in Tanzania where $90 \%$ of the participants indicated that wearing PPE affected productivity which possibly influenced them to choose not to wear PPE. In addition, a study [26] on Iran's construction industry shows that only one-third of the participants indicated 
that they were using PPE every time when working.

\section{Conclusion}

The study was aimed at investigating the OHS status in the construction industry of Windhoek, Namibia using a questionnaire. Results shows that occupational hazards are prevalent in the construction sites, however, there was a poor provision of OHS which may affect the health and quality of life of construction workers. The results also indicated that construction industry of Windhoek is dominated by male, young workers. It was concluded that due to the poor status of OHS in Windhoek construction industry, there is a need to develop a practical guidelines and to implement it on all construction sites in order to improve the OHS status in the construction industry.

\section{Ethical Aspects}

Ethical clearance was given from the University of South Africa (UNISA), Department of Health Studies research ethical committee before data collection process. Permission to conduct the study was sought and obtained from the site managers of the construction sites with participants participated in the study before data collection. Furthermore, permission was sought and obtained from the Khomas Regional Council as Windhoek is located in the Khomas region and regional council offices should sanction any research activities taking place in the region. Study a purpose was explained to the participants and consent to participate in the study was signed by the participants before the data collection process. The data collection tools were piloted, and were adapted according to the feedback from the pilot testing. Same data collection tool was used to collect the data for reliability.

\section{Acknowledgements}

The researchers would like to thank the Department of Health Studies, UNISA research ethical committee for approving this study. Furthermore, we would like to thank the chairperson for the Khomas Regional Council for granting us permission to conduct the study in Khomas region. We also thank the construction site managers for granting us permission to conduct this study on their respective construction sites. Lastly, our sincere gratitude goes to the participants who voluntarily participated in to this study.

\section{Conflicts of Interest}

Both authors have no conflicts of interest to declare.

\section{References}

[1] Choi, S.D. (2015) Aging Workers and Trade-Related Injuries in the US construction Industry. Safety and Health at Work, 6, 151-155.

https://doi.org/10.1016/j.shaw.2015.02.002 
[2] Pinto, A., Nunes, I.L. and Ribeiro, R.A. (2011) Occupational Risk Assessment in Construction Industry-Overview and Reflection. Safety Science, 49, 616-624. https://doi.org/10.1016/j.ssci.2011.01.003

[3] Pesantes-Tavares, E. (2011) Construction Worker Health : A Web-Based Approach to Selecting Alternatives to Hazardous Procedures. Doctoral thesis. University of Florida.

[4] Liao, C. and Chiang, T. (2015) The Examination of Workers' Compensation for Occupational Fatalities in the Construction Industry. Safety Science, 72, 363-370. https://doi.org/10.1016/j.ssci.2014.10.009

[5] Miller, M.R. (2012) Assessing an Educational Safety Training Solution for Latino Construction Workers. MA Dissertation. Colorado State University.

[6] Alshebani, M.N. and Wedawatta, G. (2014) Making the Construction Industry Resilient to Extreme Weather: Lessons from Construction in Hot Weather Conditions. Procedia Economics and Finance, 18, 635-642 https://doi.org/10.1016/S2212-5671(14)00985-X

[7] Verbeek, J. and Ivanov, I. (2013) Essential Occupational Safety and Health Interventions for Low- and Middle-income Countries: An Overview of the Evidence. Safety and Health at Work, 4, 77-83 https://doi.org/10.1016/j.shaw.2013.04.004

[8] Lee, W.H. (2010) Relationship between Safety Climate and Occupation Accident in Hong Kong construction Industry. Msc Dissertation, Hong Kong Baptist University, Hong Kong.

[9] Mwanaumo, E. and Thwala, W.D. (2012) Construction Practitioners' Awareness of Occupational Diseases in the Botswana Construction Industry: An Exploratory Study. Occupational Health Southern Africa, 18, 12-17.

[10] Järvholm, B. and Aström, E. (2014) The Risk of Lung Cancer after Cessation of Asbestos Exposure in Construction Workers Using Pleural Malignant Mesothelioma as a Marker of Exposure. Journal of Occupational and Environmental Medicine, 56, 1297-1301. https://doi.org/10.1097/JOM.0000000000000258

[11] Montano, D. (2014) Chemical and Biological Work-Related Risks across Occupations in Europe: A Review. Journal of Occupational Medicine and Toxicology, 9 , 113. https://doi.org/10.1186/1745-6673-9-28

[12] Health and Safety Executive (2013) Survey of Noise Emission and Risk Information Supplied with a Range of Work Machinery. Health and Safety Executive Publication, London.

[13] International Labour Organization (2015) Good Practices and Challenges in Promoting Decent Work in Construction and Infrastructure Projects. International Labour Organization, Geneva.

[14] Smallwood, J. (2011) Mass and Density of Construction Materials: Designers Knowledge, Perceptions, and Practices. Ergonomics South Africa, 23, 28-41.

[15] Himalowa, S. and Frantz, J. (2012) The Effect of Occupationally-Related Low Back Pain on Functional Activities among Male Manual Workers in a Construction Company in Cape Town, South Africa. Occupational Health Southern Africa, 18, 28-32.

[16] Smallwood, J. (2008) The Influence of Architectural Designers on Construction Ergonomics. Ergonomics South Africa, 20, 40-55.

[17] Ministry of Labour and Social Welfare of Namibia (2014) Annual Report for 2013/2014. Ministry of Labour and Social Welfare, Windhoek.

[18] Ministry of Health and Social Services of Namibia (2014) Annual Report for 
2013/2014. Ministry of Health and Social Services, Windhoek.

[19] Republic of Namibia (1997) Regulations Relating to the Health and Safety of Employees at Work. Regulation 156, in Terms of the Labour Act, 1992 (Act No. 6, 1992, as Amended). Government Printers, Windhoek.

[20] Baruah, B. (2010) Gender and Globalization. Opportunities and Constraints Faced by Women in the Construction Industry in India. Labour Studies Journal, 35, 198-221. https://doi.org/10.1177/0160449X08326187

[21] Irumba, R. (2014) Spatial Analysis of Construction Accidents in Kampala, Uganda. Safety Science, 64, 109-120.

[22] Muema, L.M., Gatebe, E., Kirui, B. and Adrian, A.A. (2015) Awareness of Construction Workers on Occupational Hazards, Illness and Injuries Associated with Construction Industry in Mombasa County. Journal of Nursing and Health Science, 4, 75-82.

[23] Salminen, S. (2015) Workplace Safety and Health. International Encyclopedia of Social \& Behavioral Sciences, 727-723.

[24] Zhao, D., McCoy, A.P., Kleiner, B. and Smith-Jackson, T.L. (2015) Control Measures of Electrical Hazards: An Analysis of Construction Industry. Safety Science, 77, 143-151.

[25] Cheng, C., Leu, S., Cheng, Y. and Lin, C. (2012) Applying Data Mining Techniques to Explore Factors Contributing to Occupational Injuries in Taiwan's Construction Industry. Accident Analysis and Prevention, 48, 214-222.

[26] Rahmani, A., Khadem, M., Madreseh, E., Aghaei, H., Raei, M. and Karchani, M. (2013) Descriptive Study of Occupational Accidents and their Causes among Electricity Distribution Company Workers at an Eight-Year Period in Iran. Safety and Health at Work, 4, 160-165.

[27] Arquillos, A.L., Romero, J.C.R. and Gibb, A. (2012) Analysis of Construction Accidents in Spain, 2003-2008. Journal of Safety Research, 43, 381-388.

[28] Zin, S.M. and Ismail, F. (2012) Employers' Behavioural Safety Compliance Factors toward Occupational, Safety and Health Improvement in the Construction Industry. Procedia-Social and Behavioral Sciences, 36, 742-751.

[29] World Health Organization (2010) WHO Healthy Workplaces: A Model for Action, for Employers, Workers, Policy-Makers and Practitioners. World Health Organization, Geneva.

[30] Roche, A.M., Lee, N.K., Battams, S., Fischer, J.A., Cameron, J. and McEntee, A. (2015) Alcohol Use among Workers in Male-Dominated Industries: A Systematic Review of Risk Factors. Safety Science, 78, 124-141.

[31] Watts, J.H. (2009) Leaders of Men: Women "Managing” in Construction. Work, Employment and Society, 23, 512-530. https://doi.org/10.1177/0950017009337074

[32] Phoya, S. (2012) The Practice of Risk Assessment, Communication and Control Health and Safety Risk Management in Building Construction Sites. Degree Thesis, Chalmers University of Technology, Gothenburg.

[33] Eppenberger, M. and Haupt, T. (2009) Construction Worker Injuries and Costs-A Comparative Study of Older and Younger Workers. Occupational Health Southern Africa, 6-13.

[34] Yoon, S.J., Lin, H.K., Chen, G., Yi, S., Choi, J. and Rui, Z. (2013) Effect of Occupational Health and Safety Management System on Work-Related Accident Rate and Differences of Occupational Health and Safety Management System Awareness between Managers in South Korea's Construction Industry. Safety and Health at 
Work, 4, 201-209.

[35] Arezes, P.M. and Bizarro, M. (2011) Alcohol Consumption and Risk Perception in the Portuguese Construction Industry. The Open Occupational Health and Safety Journal, 3, 10-17. https://doi.org/10.2174/1876216601103010010

[36] Alghadir, A. and Anwer, S. (2015) Prevalence of Musculoskeletal Pain in Construction Workers in Saudi Arabia. The Scientific World Journal, 1-5. https://doi.org/10.1155/2015/529873

[37] Herbert, J. and Iipumbu, S. (2009) Chinese Investments in Namibia, a Labour Perspective. Labour Resource and Research Institute, Windhoek.

[38] Leensen, M.C.J., van Duivenbooden, J.C. and Dreschler, W.A. (2011) A Retrospective Analysis of Noise-Induced Hearing Loss in the Dutch Construction Industry. International Archives of Occupational and Environmental Health, 84, 577-590. https://doi.org/10.1007/s00420-010-0606-3

[39] García-Herrero, S., Mariscal, M.A., García-Rodrígues, J. and Ritzel, D.O. (2012) Working Conditions, Psychological/Physical Symptoms and Occupational Accidents. Bayesian Network Models. Safety Sciences, 50, 1760-1774.

[40] Paschold, H.W. and Sergeev, A.V. (2009) Whole-Body Vibration Knowledge Survey of U.S. Occupational Safety and Health Professionals. Journal of Safety Research, 40, 171-176.

[41] Singh, J. and Khan, A.A. (2014) Effect of Coating over the Handle of a Drill Machine on a Vibration Transmissibility. Applied Ergonomics, 45, 239-246.

[42] Ahmad, S.S., Isnin, Z., Yahya, Z. and Salleh, M.M. (2013) Knowledge Sharing of Research Information for Construction Health and Safety Practices. Procedia-Social and Behavioral Sciences, 105, 239-248.

[43] Meo, S.A., Alsaaran, Z.F., Alshehri, M.K., Khashougji, M.A., Almeterk, A.A.Z., Almutairi, S.F. and Alsaeed, S.F. (2013) Work-Related Symptoms among Building Construction Workers in Riyadh, Saudi Arabia. Pakistan Journal of Medical Sciences, 29, 1394-1399. https://doi.org/10.12669/pjms.296.4052

[44] Boschman, J.S., Van der Molen, H.F., Sluiter, J.K. and Frings-Dresen, M.H. (2012) Musculoskeletal Disorders among Construction Workers: A One-Year Follow-Up Study. BMC Musculoskeletal Disorders, 196, 1-9.

[45] Akram, M. (2014) Occupational Disease and Public Health Concerns of Migrant Construction Workers: A Social Epidemiological Study in Western Ultar Pradesh. Social Change, 44, 97-117. https://doi.org/10.1177/0049085713514828

[46] Abrey, M. and Smallwood, J.J. (2014) The Effects of Unsatisfactory Working Conditions on Productivity in the Construction Industry. Procedia Engineering, 85, 3-9.

[47] Acharya, S.R. (2014) Utilization Pattern of Personal Protective Equipment among Industrial Workers of Nawalparasi, Nepal. Journal of Public Health, 13, 24-28. https://doi.org/10.3126/hprospect.v13i2.11833 
Submit or recommend next manuscript to SCIRP and we will provide best service for you:

Accepting pre-submission inquiries through Email, Facebook, LinkedIn, Twitter, etc. A wide selection of journals (inclusive of 9 subjects, more than 200 journals)

Providing 24-hour high-quality service

User-friendly online submission system

Fair and swift peer-review system

Efficient typesetting and proofreading procedure

Display of the result of downloads and visits, as well as the number of cited articles Maximum dissemination of your research work

Submit your manuscript at: http://papersubmission.scirp.org/

Or contact ojsst@scirp.org 